\title{
Resistência à penetração e agregação de um Latossolo Amarelo sob monocultivo de soja e de eucalipto no cerrado do Piauí
}

\section{Resistance to penetration and aggregation of a Yellow Oxisol under monocropping of soybean and eucalyptus in a savannah of Piauí state, Brazil}

\author{
Thiago Vinicius Barros IBIAPINA ${ }^{1,2}$; Adeodato Ari Cavalcante SALVIANO ${ }^{3}$; \\ Luís Alfredo Pinheiro Leal NUNES ${ }^{4}$; Francisco Edinaldo Pinto MOUSINHO ${ }^{5}$; \\ Milcíaldes Gadelha de LIMA ${ }^{6}$; Laércio Moura dos Santos SOARES ${ }^{7}$ \\ ${ }^{1}$ Parte da dissertação de mestrado do primeiro autor; Pesquisa financiada pelo CNPq \\ ${ }^{2}$ Engenheiro Agrônomo, Doutorando em Ciência do Solo, Universidade Estadual de Sâo Paulo; \\ ibiapina.thiago@gmail.com \\ ${ }^{3}$ Engenheiro Agrônomo, Universidade Federal do Piauí, Doutor em Solos e Nutrição de Plantas, Universidade \\ Federal do Piauí; adeodatosalviano@hotmail.com \\ ${ }^{4}$ Autor para correspondência, Engenheiro Agrônomo, Doutor em Solos e Nutrição de Plantas, Universidade \\ Federal do Piauí, Departamento de Engenharia Agrícola e Solos, Campus Ministro Petrônio Portela, Bairro \\ Ininga, Teresina-PI, CEP: 64049-550; luisalfredo@ufpi.edu.br \\ 5 Engenheiro Agrônomo, Doutor em Engenharia Agrícola, Colégio Técnico de Teresina; fepmousi@yahoo.com.br \\ ${ }^{6}$ Engenheiro Agrônomo, Doutor em Agronomia, Universidade Federal do Piauí; gadelhaenator@gmail.com \\ ${ }^{7}$ Engenheiro Agrônomo, Universidade Federal do Piauí; laercio.moura@hotmail.com
}

Recebido em: 28-01-2014; Aceito em: 13-05-2014

\begin{abstract}
Resumo
A qualidade física do solo é essencial para a sustentabilidade dos agroecossistemas, pois está relacionada com processos fundamentais para o desenvolvimento das culturas agrícolas. O objetivo deste trabalho foi investigar os impactos do manejo do solo sobre os atributos físicos de monocultivos de soja e eucalipto. Foram avaliados a resistência à penetração, agregação e carbono orgânico total em solos sob monocultivo de soja e eucalipto com 2 e 4 anos em relação a uma mata nativa de cerrado que foi usada como controle. Observaram-se maiores valores de resistência à penetração para sistemas com preparo convencional e cultivado com soja a partir da profundidade $0,10 \mathrm{~m}$, alcançando o valor 6,0 MPa, classificado como muito alto. O cerrado nativo e o eucalipto cultivado após a derrubada da mata propiciaram menor resistência à penetração ao longo do perfil com valores classificados nas classes baixa e moderada. O sistema sob manejo convencional modificou a estrutura do solo, resultando em menor proporção de solo nas maiores classes de agregados e índice de estabilidade de agregados. O monocultivo do eucalipto, por meio do cultivo mínimo, preservou as características físicas originais do solo.
\end{abstract}

Palavras-chave adicionais: carbono orgânico; manejo convencional; qualidade física do solo.

\begin{abstract}
Soil physical quality is essential for sustainability of agroecosystems since it is related to key processes for the development of agricultural crops. The objective of this experiment was to investigate the impacts of soil management on the physical attributes of the soil when cultivated with soybean and eucalyptus monocropping. Soil resistance to penetration, aggregation, and total organic carbon under cultivation of 2 and 4 year old soybean and eucalyptus were evaluated. These results were compared with those of a native forest growing in a Savannah region. Higher resistance to penetration values were found when the soil was prepared by the conventional method and cultivated with soybean. This increment in resistance to penetration increased as depth in the soil surpassed $10 \mathrm{~cm}$, reaching the value of $6.0 \mathrm{MPa}$, that is, a very high value. The native savannah and the cultivated eucalyptus were the conditions in which resistance to penetration was between low and medium. The system under the conventional system modified soil structure and this caused lower proportion at the larger aggregate classes and aggregate stability index. The monocropping of eucalyptus, due to minimum tillage, was the system capable of preserving the original physical characteristics of the soil.
\end{abstract}

Additional keywords: conventional tillage; organic carbon; soil physical quality. 


\section{Introdução}

O cerrado piauiense ocupa aproximadamente 11,5 milhões de hectares, $46 \%$ da área total do Estado. A unidade de mapeamento mais representativa é o Latossolo Amarelo, que apresenta elevado potencial para exploração agropecuária, e nos últimos anos vem sendo utilizada com o cultivo de culturas para a produção de grãos (AGUIAR \& MONTEIRO, 2005). Contudo, recentemente, as áreas sob vegetação de cerrado no Piauí vêm sendo gradativamente substituídas por pastagens e florestas plantadas, como o eucalipto.

A exploração agrícola dessas áreas com culturas anuais ocorre por meio de sistemas de manejo com intenso revolvimento do solo, provocando modificações em suas propriedades originais. O preparo convencional do solo rompe os agregados da camada preparada e acelera a decomposição da matéria orgânica, refletindo negativamente na infiltração e retenção de água, aeração, selamento e encrostamento superficial, o que tem levado à diminuição da produtividade do solo e à consequente degradação do solo (BEUTLER et al., 2001; SILVA et al., 2005).

Por sua vez, na implantação da cultura do eucalipto, não há muita degradação ao solo, e o preparo do mesmo, normalmente, é feito por meio de cultivo mínimo onde o subsolador é o único implemento usado, e os resíduos culturais são mantidos sobre a superfície do solo. Ademais, as plantações de eucalipto constituem opção efetiva de captura de carbono, podendo imobilizar, pelo menos, 50 t ha $^{-1} \mathrm{ano}^{-1}$ de $\mathrm{CO}_{2}$ da atmosfera, evidenciando ainda grande acúmulo de matéria orgânica pela constante queda de folhas e galhos, formando densa serapilheira, o que garante boa qualidade física do solo (GATTO et al., 2010).

O monitoramento da qualidade do solo pelo uso de seus atributos físicos é de grande importância para a manutenção e avaliação da sustentabilidade dos sistemas agrícolas. Assim, a avaliação do efeito das alterações do manejo na qualidade do solo no cerrado é fundamentada na mensuração de alguns atributos físicos do solo, como a estabilidade de agregados do solo (COLONEGO \& ROSOLEM, 2008; FONTENELE et al., 2009; ARAÚJO et al., 2010) e a resistência à penetração (CAVENAGE et al., 1999; BEUTLER et al., 2001).

A estabilidade de agregados é a principal propriedade física do solo afetada pela matéria orgânica, visto que a aproximação e a cimentação das partículas do solo ocorrem mediante a atuação de diversas substâncias de natureza mineral e orgânica, por meio de mecanismos físicos, químicos e biológicos (SILVA et al., 2005). Por conseguinte, as demais propriedades do solo, indiretamente, também são influenciadas, tais como a porosidade, a infiltração, a retenção de água no solo e a densidade, dentre outras.

A resistência do solo à penetração aumenta com a compactação do solo, sendo restritiva ao crescimento radicular acima de certos valores. Esse aspecto está relacionado com a permanência da continuidade dos poros, resultante da decomposição das raízes, liberação de exsudatos radiculares, atividade biológica mais efetiva, produzindo agentes colantes ou cimentantes (polissacarídeos de alta viscosidade e substâncias húmicas) e propiciando maior estabilidade dos agregados (TISDAL \& OADES, 1982).

Dessa forma, este trabalho teve como objetivo investigar os impactos do manejo do solo sobre os atributos físicos de monocultivos de soja e eucalipto.

\section{Material e métodos}

O estudo foi realizado na fazenda Chapada Grande, no município de Regeneração-PI (06 ${ }^{\circ} 14$ " 16" S, 42 41' 18" O). O solo, segundo levantamento exploratório-reconhecimento do solo do Estado do Piauí, é do tipo Latossolo Amarelo distrófico (JACOMINE et al., 1986). A região apresenta temperatura média anual de $32^{\circ} \mathrm{C}$, altitude de $326 \mathrm{~m}$ e precipitação média anual de $1.350 \mathrm{~mm}$, com chuvas distribuídas de janeiro a maio (Regime Equatorial Continental, com isoietas anuais entre 800 e $1.400 \mathrm{~mm}$ ). O clima, segundo a classificação climática de Köppen, é do tipo (Aw').

Foram escolhidas quatro áreas adjacentes com diferentes manejos: eucalipto com quatro anos de idade; eucalipto com dois anos de idade; cultivo de soja por três anos, precedidos por arroz e milho por dois anos em sistema convencional e mata nativa de cerrado preservada (Tabela 1).

A análise granulométrica foi realizada pelo método da pipeta (EMBRAPA, 2005). As áreas apresentaram texturas semelhantes, com teores de argila variando entre 400 e $450 \mathrm{~g} \mathrm{~kg}^{-1}$, nas três camadas, o que os inclui na classe textural de solos argilosos, com exceção de E4 nas camadas de $0-0,10$ e 0,10 - 0,20 m, que apresentou um teor de argila de 348 e $368 \mathrm{~g} \mathrm{~kg}^{-1}$, respectivamente, que corresponde à classe franco-argiloso (Tabela 2).

A resistência do solo à penetração foi realizada em solo com umidade gravimétrica variando de 20 a $22 \%$ até a camada de $0,30 \mathrm{~m}$ (Tabela 3), utilizando-se de penetrômetro de impacto, modelo IAA/Planalsucar - Stolf, por meio da penetração de uma haste no solo a partir de impactos de um peso em queda livre a uma altura de $40 \mathrm{~cm}$ (STOLF, 1991). A equação é a seguinte: $R P=(5,6+6,89) N 0,0980665$

Em que:

$\mathrm{RP}$ - resistência do solo à penetração em MPa;

$\mathrm{N}$ - número de impactos por decimetro de penetração. 
Tabela 1 - Histórico do manejo e adubação das áreas estudadas. Management history and fertilization of the studied areas.

\begin{tabular}{|c|c|}
\hline Área & Histórico \\
\hline $\begin{array}{l}\text { Plantio convencional } \\
\text { com soja } \\
\text { (CS) }\end{array}$ & $\begin{array}{l}\text { Área desmatada, em } 2005 \text {, com enleiramento e queima dos galhos e } \\
\text { folhas. A madeira foi destinada para carvão. O preparo inicial do solo } \\
\text { consistiu em aração, sulcamento, catação de raízes e incorporação de } \\
4 \mathrm{t} \mathrm{ha}^{-1} \text { de calcário e adubação de } 250 \mathrm{~kg} \mathrm{ha}^{-1} \text { de NPK. A área vem sendo } \\
\text { cultivada com soja pelo terceiro ano consecutivo, com uso de sementes } \\
\text { inoculadas, sendo precedido pelas culturas de arroz e milho por dois anos. } \\
\text { O preparo de solo para plantio, a colheita e a aplicação de adubos e } \\
\text { defensivos agrícolas vêm sendo feitos de forma mecanizada. }\end{array}$ \\
\hline $\begin{array}{l}\text { Eucalipto com } 2 \text { anos } \\
\text { (E2) }\end{array}$ & $\begin{array}{l}\text { Área desmatada em } 2008 \text {, com enleiramento e queima dos galhos e folhas. } \\
\text { A madeira foi destinada para carvão. O preparo inicial do solo consistiu em } \\
\text { gradeamento e sulcamento para plantio, incorporação de } 4 \mathrm{t} \mathrm{ha}^{-1} \text { de } \\
\text { calcário e } 400 \mathrm{~kg} \mathrm{ha}^{-1} \text { de superfosfato triplo. O plantio de eucalipto foi } \\
\text { realizado em } 2008 \text {, utilizando-se de espaçamento de } 3,5 \times 2,5 \mathrm{~m} \text {. Procedeu- } \\
\text { se a uma adubação de cobertura com NPK }(20-00-20) \text {, com } 150 \mathrm{~kg} \mathrm{pé}^{-1} \text {. }\end{array}$ \\
\hline $\begin{array}{l}\text { Eucalipto com } 4 \text { anos } \\
\text { (E4) }\end{array}$ & $\begin{array}{l}\text { Área desmatada e plantada em 2006, com manejo e adubação similar a } \\
\text { E2. Esta área foi utilizada nos anos de } 2004 \text { e } 2005 \text {, com o cultivo de } \\
\text { milho, com uso de aração e gradagem. }\end{array}$ \\
\hline $\begin{array}{l}\text { Mata nativa } \\
\text { (MN) }\end{array}$ & Cerrado nativo preservado. \\
\hline
\end{tabular}

Tabela 2 - Caracterização textural de um Latossolo Amarelo sob diferentes sistemas de manejo. Textural characteristics of the Yellow Oxisol used in this experiment.

\begin{tabular}{|c|c|c|c|c|}
\hline Camada (m) & Argila & Areia fina & Areia grossa & Silte \\
\hline & \multicolumn{4}{|c|}{ CS } \\
\hline $0-0,10$ & 402 & 190 & 111 & 297 \\
\hline $0,10-0,20$ & 401 & 182 & 118 & 299 \\
\hline \multirow[t]{2}{*}{$0,20-0,30$} & 424 & 208 & 96 & 273 \\
\hline & \multicolumn{4}{|c|}{ E2 } \\
\hline $0-0,10$ & 402 & 186 & 114 & 298 \\
\hline $0,10-0,20$ & 424 & 180 & 104 & 292 \\
\hline \multirow[t]{2}{*}{$0,20-0,30$} & 444 & 179 & 95 & 283 \\
\hline & \multicolumn{4}{|c|}{ E4 } \\
\hline $0-0,10$ & 348 & 183 & 141 & 328 \\
\hline $0,10-0,20$ & 368 & 199 & 129 & 305 \\
\hline \multirow[t]{2}{*}{$0,20-0,30$} & 421 & 204 & 105 & 270 \\
\hline & \multicolumn{4}{|c|}{ MN } \\
\hline $0-0,10$ & 419 & 178 & 146 & 257 \\
\hline $0,10-0,20$ & 442 & 139 & 128 & 290 \\
\hline $0,20-0,30$ & 459 & 161 & 104 & 276 \\
\hline
\end{tabular}

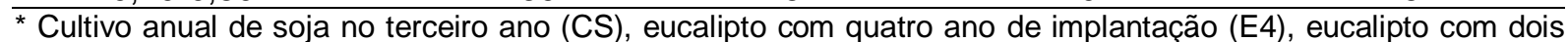
anos de implantação (E2) e área de mata nativa de cerrado (MN).

Tabela 3 - Umidade gravimétrica em um Latossolo Amarelo sob diferentes sistemas de manejo. Gravimetric humidity of the Yelow Oxissol under different cropping systems.

\begin{tabular}{ccccc}
\hline Camada $(\mathrm{m})$ & CS & E2 & E4 & MN \\
\hline $0-0,10$ & 22,75 & 24,39 & 23,42 & 23,50 \\
$0,10-0,20$ & 23,64 & 21,14 & 19,51 & 23,69 \\
$0,20-0,30$ & 18,83 & 19,01 & 17,32 & 19,91 \\
Média & 21,74 & 21,51 & 20,08 & 22,37 \\
\hline
\end{tabular}

${ }^{*}$ Cultivo anual de soja no terceiro ano (CS); eucalipto com quatro anos de implantação (E4); eucalipto com dois anos de implantação (E2), e área de mata nativa de cerrado (MN). 
Os valores de resistência do solo à penetração foram calculados a partir de $0,05 \mathrm{~m}$ de profundidade. A partir dos valores obtidos, as camadas foram discriminadas com relação ao seu grau de compactação de acordo com USDA, 1993, que considera o limite de $2 \mathrm{MPa}$ como forte restrição ao crescimento radicular.

As amostras de solo para a avaliação da agregação foram coletadas em cinco pontos diferentes de cada área, em três camadas: $0-0,10$; 0,10-0,20 e 0,20-0,30 m. A análise da estabilidade de agregados foi realizada de acordo com EMBRAPA (2005), em que os agregados tamisados foram separados em peneiras de $4 \mathrm{~mm}$ e $2 \mathrm{~mm}$. Os agregados retidos na peneira de menor diâmetro foram levados para a distribuição de classes via úmida, em aparelho de oscilação vertical, onde o conteúdo de cada peneira, com malhas de 2,0; 1,0;0,5;0,25 e $0,105 \mathrm{~mm}$ de abertura, respectivamente, foi levado à estufa a $105^{\circ} \mathrm{C}$ até massa constante.

O conteúdo da classe menor que $0,105 \mathrm{~mm}$ foi estimado por diferença, considerando a umidade residual da amostra. A partir das massas das classes obtidas, foram calculados o diâmetro médio ponderado (DMP), o diâmetro médio geométrico (DMG) e o índice de estabilidade de agregados (IEA), de acordo com as seguintes equações:

$\mathrm{DMP}=\sum_{\mathrm{i}=1}^{\mathrm{n}}(\mathrm{xi}$ wi)

$D M G=\exp \left[\frac{\sum_{i=1}^{n} w i \log x i}{\sum_{i=1}^{n} w i}\right]$

$\mathrm{IEA}=\left[\frac{\text { mas-wp25-areia }}{\text { mas-areia }}\right] 100$

Em que:

$\mathrm{n}$ : número de classes;

xi: diâmetro médio das classes de agregados;

wi: proporção de cada classe em relação ao total, mas: massa da amostra seca, e

wp25: massa dos agregados da classe $<0,25 \mathrm{~mm}$.

Foi determinado, ainda, o carbono orgânico total (COT) por oxidação da matéria orgânica via úmida $\mathrm{K}_{2} \mathrm{Cr}_{2} \mathrm{O}_{7} 0,167 \mathrm{~mol} \mathrm{~L}^{-1}$ em meio sulfúrico, com aquecimento externo (EMBRAPA, 2005).

Os resultados foram submetidos à análise de variância, sendo as médias comparadas pelo teste de Tukey, em nível de $5 \%$ de probabilidade, utilizando-se do sistema computacional ASSISTAT, versão 7.4 beta.

\section{Resultados e discussão}

A perda inicial de carbono orgânico (COT) total com sistemas de manejo que envolve culturas anuais com intenso revolvimento do solo, por meio de aração e gradagens, é fato conhecido, como pode ser observado pelos menores teores apresentados pelo cultivo anual de soja no terceiro ano (CS), em relação aos outros sistemas de manejo (Tabela 4). Mas, a sustentabilidade de um sistema requer a recuperação mais rápida dos teores originais de COT no solo, após a derrubada da vegetação original.

O aumento da idade do eucalipto elevou os teores de COT em todas as camadas, atingindo valores superiores àqueles observados em solos sob condição natural, resultados parecidos aos encontrados por BARRETO et al. (2008) e MIRANDA et al. (2007), provavelmente, devido à maior produção de resíduos orgânicos nessa cobertura vegetal que os repõe via decomposição mais lenta. Ademais, outros estudos apontam um aumento de COT em plantações de eucalipto em solos argilosos (ZINN et al., 2002; GAMA-RODRIGUES et al., 2005). Esse fato pode ser atribuído à ação da interação da argila com a matéria orgânica, preservando-a da biodegradação (PULROLNIK et al., 2009).

Tabela 4: Carbono orgânico total em um Latossolo Amarelo sob diferentes sistemas de manejo. Total organic carbon of the Yellow Oxisol under different cropping systems.

\begin{tabular}{ccccc}
\hline \multirow{2}{*}{ Profundidade $(\mathrm{m})$} & \multicolumn{5}{c}{${ }^{(*)}$ Sistemas de manejo } \\
\cline { 2 - 5 } & CS & E02 & E04 & MN \\
\hline $0-0,10$ & $24,74 \mathrm{c}$ & $54,10 \mathrm{~b}$ & $77,36 \mathrm{a}$ & $47,40 \mathrm{~b}$ \\
$0,10-0,20$ & $25,12 \mathrm{c}$ & $53,36 \mathrm{ab}$ & $68,90 \mathrm{a}$ & $46,28 \mathrm{~b}$ \\
$0,20-0,30$ & $27,20 \mathrm{c}$ & $42,18 \mathrm{ab}$ & $58,50 \mathrm{a}$ & $43,72 \mathrm{~b}$ \\
Média & 25,68 & 49,88 & 68,25 & 45,80 \\
\hline
\end{tabular}

CS - Cultivo anual de soja no terceiro ano; E4 - eucalipto com quatro anos de implantação; E2 - eucalipto com dois anos de implantação; MN - área de mata nativa de cerrado. ${ }^{(*)}$ Médias seguidas por mesma letra em coluna não diferem estatisticamente, pelo teste de Tukey, a 5\% de probabilidade.

A fitomassa, além de provocar maior acúmulo de COT, também influencia as propriedades físicas do solo, uma vez que atua como barreira física entre 0 solo e a atmosfera (CAMPOS et al., 1995). Para os autores, solos com maior cobertura impedem ou diminuem a ação direta das gotas de chuva, mantêm a umidade e a temperatura mais uniformes, as quais favorecem o desenvolvimento do sistema radicular e a atividade microbiana nas camadas su- 
perficiais do solo, e contribuem para a criação de um ambiente mais favorável à sua agregação.

Verificou-se um aumento abrupto do valor de RP, após a camada de $0,15 \mathrm{~m}$ de profundidade, para o sistema de manejo CS (Figura 1). Tal aspecto está relacionado ao sistema de manejo convencional, visto que operações com má- quinas agrícolas pesadas, realizadas com relativa intensidade, em áreas de culturas anuais, proporcionam a compactação do solo devido às pressões exercidas, além da ação do arado que vai normalmente até a profundidade de $0,20 \mathrm{~m}$ (BEUTLER et al., 2001).

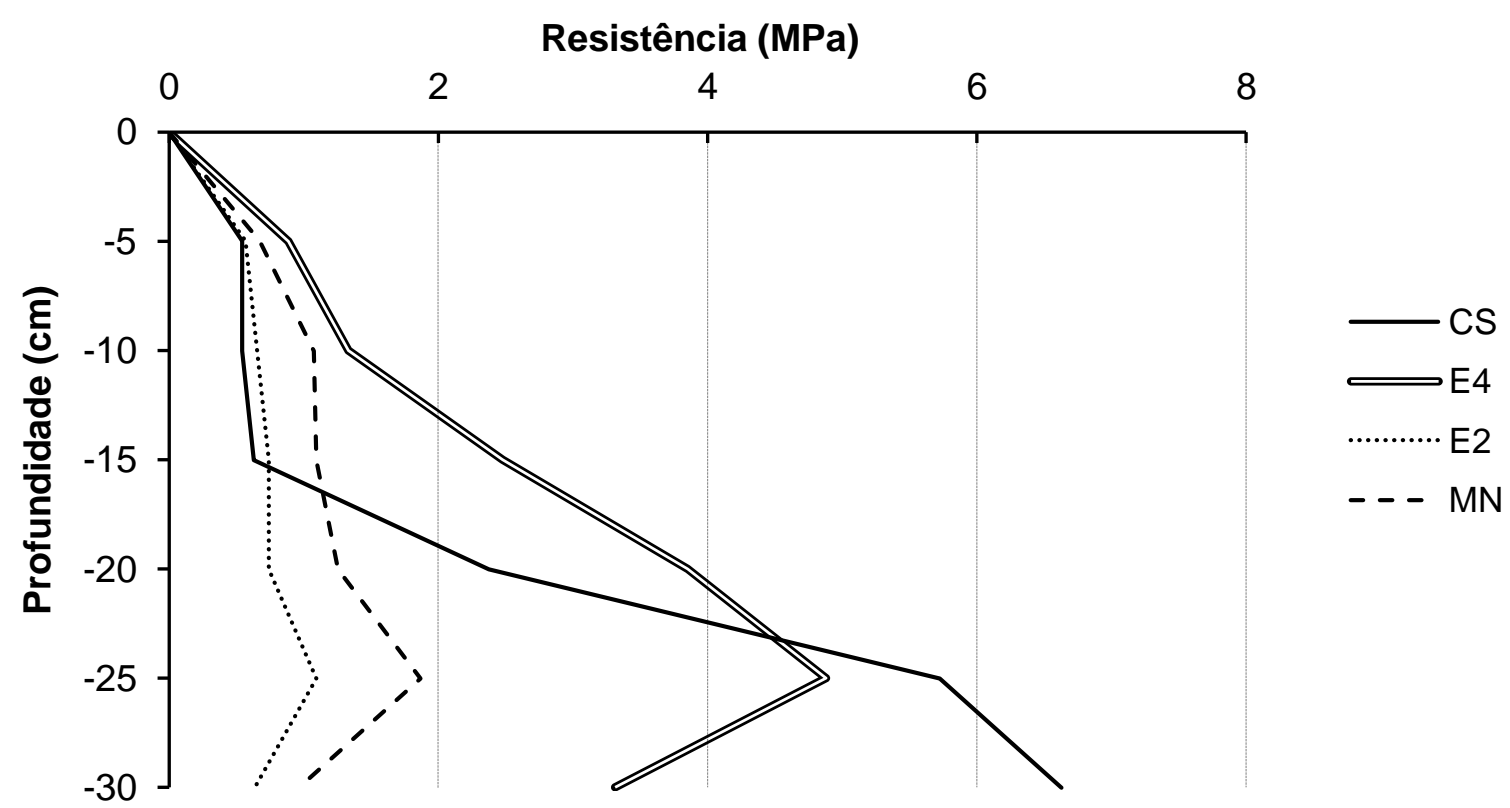

CS - Cultivo anual de soja no terceiro ano; E4 - eucalipto com quatro anos de implantação; E2 - eucalipto com dois anos de implantação; MN - área de mata nativa de cerrado.

Figura 1 - Resistência do solo à penetração sob diferentes sistemas de manejo. Soil resistance to penetration under different cropping systems.

Em alguns estudos, tem-se observado que sistemas de manejo convencional mostram alta e muito alta RSP, sobretudo em períodos longos de uso do solo. BEUTLER et al. (2001), estudando uma área de cerrado nativo com plantio de milho de modo convencional, com arado de disco e por plantio direto por oito anos consecutivos, obtiveram valores de RP (resistência do solo à penetração) compreendidos na classe alta, a partir de $0,15 \mathrm{~m}$ para plantio convencional e na camada de $0,25 \mathrm{~m}$ no manejo convencional, com arado de disco. Os autores atribuíram esses valores elevados ao tráfego de máquinas e ação do arado de disco sempre na mesma camada, além do tempo de condução do experimento.

Já no sistema E4 (eucalipto com quatro anos de implantação), maior RP a partir da camada $0,10 \mathrm{~m}$ deveu-se à utilização também do sistema de manejo convencional por dois anos, com plantio de soja e milho, antes da instalação do eucalipto. Isso provavelmente teria deixado camadas mais compactadas do que o ideal para a implantação da cultura do eucalipto, além de não ter sido realizado a subsolagem por ocasião do plantio da cultura. Resultados semelhantes foram encontrados por CANEVAGE et al. (1999), em um Latossolo Vermelho-Escuro de textura franco-argilosa, que observaram que áreas com eucalipto e pínus com dez anos de cultivo apresentaram maiores valores de RP, quando implantados em uma área que foi manejada com cultivo convencional, com a cultura do milho por oito anos consecutivos.

A partir do $0,15 \mathrm{~m}$ no sistema CS (cultivo anual de soja) e a partir de 0,20 m no sistema E4 (eucalipto om quatro anos de implantação), os valores de RP verificados são superiores ao limite de 2,0 MPa, considerado por USDA (1993) como restritivo ao desenvolvimento de raízes. Outras pesquisas mostraram que foi verificado que a produtividade máxima da soja esteve associada à RSP de 1,57 a $1,59 \mathrm{MPa}$, até a camada de $0,35 \mathrm{~m}$ (VASQUEZ et al., 1989), e de 1,80 MPa em um Latossolo argiloso (SILVA et al., 2000), valores estes bem inferiores aos encontrados na RP da soja neste trabalho. Os sistemas MN (mata nativa de cerrado) e E4 mostraram RP na classe baixa ao longo do perfil estudado.

O sistema de manejo CS mostrou os menores valores de diâmetro médio ponderado (DMP) dos agregados em todas as camadas 
avaliadas (Tabela 5). Outras pesquisas em áreas de cerrado constataram que os valores de DMP foram menores em todos os sistemas de cultivo convencional onde o preparo do solo foi realizado, com a combinação de aração pesada e gradagens, com o intuito de criar condições favoráveis ao monocultivo da soja, em relação à mata natural (FONTENELE et al., 2009; CORREIA, 2002). CASTRO FILHO et al. (1998), estudando a estabilidade de agregados, afirma- ram que o manejo convencional do solo promove a ruptura de agregados, ocasionada pelo intenso revolvimento do solo, o que pode comprometer a estabilidade de agregados e a redução do DMP (diâmetro médio ponderado) nos cultivos seguintes com adoção desse sistema. Esse fato também pode ser atribuído ao valor menor dessa variável em E4, na camada superficial, uma vez que essa área sofreu um manejo intensivo similar a CS, dois anos antes de sua implantação.

Tabela 5 - Valores de Diâmetro Médio Geométrico (DMG), Diâmetro Médio Ponderado (DMP) e Índice de Estabilidade de Agregados (IEA) sob diferentes sistemas de manejo e área de cerrado nativo. Geometric mean diameter values (DMG) weighted average Diameter (DMP) and aggregate stability index (IEA) under different cropping systems.

\begin{tabular}{|c|c|c|c|c|}
\hline \multirow{2}{*}{ Camada (m) } & \multicolumn{4}{|c|}{${ }^{(*)}$ Sistemas de manejo } \\
\hline & CS & E2 & $\mathrm{E} 4$ & MN \\
\hline & \multicolumn{4}{|c|}{ DMP } \\
\hline $0-0,10$ & $5,51 \mathrm{~b}$ & $6,85 a$ & $5,68 b$ & $7,49 a$ \\
\hline $0,10-0,20$ & $5,54 \mathrm{~b}$ & $6,93 \mathrm{a}$ & $6,72 \mathrm{a}$ & $7,10 \mathrm{a}$ \\
\hline \multirow[t]{2}{*}{$0,20-0,30$} & $5,74 \mathrm{~b}$ & $6,28 \mathrm{a}$ & $6,37 \mathrm{ab}$ & $7,53 \mathrm{a}$ \\
\hline & \multicolumn{4}{|c|}{ DMG } \\
\hline $0-0,10$ & $1,45 b$ & $1,58 \mathrm{ab}$ & $1,49 \mathrm{~b}$ & $1,66 \mathrm{a}$ \\
\hline $0,10-0,20$ & $1,39 \mathrm{~b}$ & $1,46 a b$ & $1,58 \mathrm{a}$ & $1,62 \mathrm{a}$ \\
\hline \multirow[t]{2}{*}{$0,20-0,30$} & $1,44 \mathrm{~b}$ & $1,50 a b$ & $1,56 \mathrm{a}$ & $1,65 \mathrm{a}$ \\
\hline & \multicolumn{4}{|c|}{ IEA } \\
\hline $0-0,10$ & $36,81 \mathrm{c}$ & $55,05 \mathrm{~b}$ & $42,37 \mathrm{c}$ & $89,50 \mathrm{a}$ \\
\hline $0,10-0,20$ & $41,14 \mathrm{~b}$ & $41,71 \mathrm{~b}$ & $57,63 \mathrm{~b}$ & $84,50 \mathrm{a}$ \\
\hline $0,20-0,30$ & $46,78 \mathrm{~b}$ & $56,26 \mathrm{~b}$ & $50,51 \mathrm{~b}$ & $89,56 \mathrm{a}$ \\
\hline
\end{tabular}

CS - Cultivo anual de soja no terceiro ano; E4 - eucalipto com quatro anos de implantação; E2 - eucalipto com dois anos de implantação; MN - área de mata nativa de cerrado. ${ }^{(*)}$ Médias seguidas por mesma letra na mesma linha não diferem estatisticamente, pelo teste de Tukey, a $5 \%$ de probabilidade.

Por outro lado, MN e E2 apresentaram os maiores valores de DMP em todas as camadas avaliadas, com exceção de E4 na camada $0,20-0,30 \mathrm{~m}$. Isso pode ser atribuído, no caso de $\mathrm{MN}$, ao estado de equilíbrio em que se encontra o sistema, favorecendo a manutenção e a estabilidade dos agregados. Solo sob vegetação nativa, em geral, mostram maior estrutura conectada a um maior conteúdo de material orgânico, provavelmente resultante de uma série de fatores que considera alguma diferença em quantidade e qualidade de matéria orgânica incorporada no solo, bem como a existência de condições climáticas que favorecem o desenvolvimento de vegetação (LONGO et al., 1999), como reportado neste estudo. Em E2, ao contrário de E4, a implantação da cultura deu-se após a derrubada da mata nativa e as operações com máquinas agrícolas resumiram-se à subsolagem $\mathrm{e}$ à gradagem da área antes e após o plantio, respectivamente.

O DMG do solo sob MN e E2 apresentou valores superiores aos encontrados nos sistemas de manejo estudados no presente experimento, nas três camadas, o que demonstra mais claramente o efeito do tráfego de maquinário agrícola utilizado nos dois sistemas, CS e E4, na estabilidade dos agregados do solo. O intenso revolvimento do solo leva à quebra de estruturas de macro e de microagregados, e, consequentemente, à perda da proteção física da MOS, bastante significativa em solos muito argilosos e oxídicos (WILCKE \& LILIENFEIN, 2004; JANDL et al., 2007), como os deste estudo. Com essa quebra de agregados, coloides orgânicos (solúveis na solução do solo ou não) antes incorporados à estrutura do solo podem estar se eluviando no perfil do solo, com consequente aumento do estoque de COT em profundidade, conforme observado em CS nesta pesquisa e por VERGUTZ et al. (2010).

Com relação ao IEA, o sistema MN mostrou valores significativamente superiores aos demais sistemas de manejo estudados em todas as camadas (Tabela 5), visto que o Cerrado se encontra em equilíbrio, uma vez que não existe movimentação do solo por implementos agrícolas com sua consequente desagregação, à seme- 
Ihança do que foi constatado por ARAÚJO et al. (2010) e MENDES et al. (2003).

$\mathrm{Na}$ camada de 0,0 a $0,10 \mathrm{~m}$, o sistema $\mathrm{E} 4$ exibiu menores valores de DMP, DMG e IEA apesar de mostrar maior conteúdo de carbono orgânico. Portanto, o aumento desses valores nas camadas mais profundas é, provavelmente, em função do uso de plantio convencional por dois anos antes de implantação da cultura, o que provavelmente levou ao rompimento dos agregados na camada superficial. No entanto, os teores de carbono orgânico diminuiu com a profundidade, o que supostamente poderia contribuir para diminuir também os valores dessa variável ao longo do perfil do solo.

Os atributos físicos utilizados nesta pesquisa, como indicadores de qualidade do solo, mostraram bom desempenho na distinção dos efeitos proporcionados pelos sistemas de manejo com uso de máquinas pesadas em relação ao sistema com cultivo mínimo e em equilíbrio, contribuindo para o monitoramento do manejo sustentável de solos do cerrado piauiense.

\section{Conclusões}

Práticas de revolvimento periódico do solo reduziram os valores de resistência à penetração do solo.

A estabilidade de agregados do solo sob cultivo de soja apresentou menores valores quando comparados às áreas cultivadas com eucalipto.

O monocultivo do eucalipto por meio do cultivo mínimo preserva as características físicas originais do solo.

\section{Agradecimentos}

Os autores agradecem ao Conselho Nacional de Desenvolvimento Científico e Tecnológico (CNPq), pelo auxílio financeiro e logístico.

\section{Referências}

AGUIAR, T. J. A.; MONTEIRO, M. S. L. Modelo agrícola e desenvolvimento sustentável: a ocupação do cerrado piauiense. Ambiente \& Sociedade, Campinas, v.8, n.1, p.161-178, 2005.

ARAÚJO, F. S.; SALVIANO, A. A. C.; LEITE, L. F. C.; SOUZA, Z. M.; SOUSA, A. C. M. Physical quality of a yellow latossol under integrated croplivestock system. Revista Brasileira de Ciência do Solo, Viçosa, MG, v.34, n.3, p.717-723, 2010.

BARRETO, P. A. B.; GAMA-RODRIGUES, E. F.; GAMA-RODRIGUES, A.C., BARROS, N. F.; FONSECA., S. Atividade microbiana, carbono e nitrogênio da biomassa microbiana em plantações de eucalipto, em sequencia de idades, Revista Brasileira de Ciência do Solo, Viçosa, MG, v.32, n.2, p.611-619, 2008.
BEUTLER, A. N.; SILVA, M. L. N.; CURI, N.; FERREIRA, M. M.; CRUZ, J. C.; PEREIRA FILHO, I. A.. Resistência à penetração e permeabilidade de Latossolo Vermelho distrófico típico sob sistemas de manejo na região dos cerrados. Revista Brasileira de Ciência do Solo, Viçosa, MG, v.25, n.1, p.167-177, 2001.

CAMPOS, B. C.; REINERT, D. J.; NICOLODI, R.; RUEDELL, J.; PETRERE, C. Estabilidade estrutural de um Latossolo Vermelho-Escuro distrófico após sete anos de rotação de culturas e sistemas de manejo de solo. Revista Brasileira de Ciência do Solo, Viçosa, MG, v.19, n.1, p.121-126, 1995.

CASTRO FILHO, C.; MUZILLI, O.; PODANOSCHI, A. L. Estabilidade dos agregados e sua relação com o teor de carbono orgânico num Latossolo Roxo distrófico, em função de sistemas de plantio, rotações de culturas e métodos de preparo de amostras. Revista Brasileira de Ciência do Solo, Viçosa, MG, v.22, n.3, p.527-538, 1998.

CAVENAGE, A. ; MORAES, M. L. T. ; ALVES, M. C.; CARVALHO, M. A. C.; FREITAS, M. L. M. ; BUZETTI, S. Alterações nas propriedades físicas de um Latossolo vermelho-escuro sob diferentes culturas. Revista Brasileira de Ciência do Solo, Viçosa, MG, v.23, n.4, p.997-1003, 1999.

COLONEGO, J. C.; ROSOLEM, C. A. Estabilidade de agregados do solo após manejo com rotações de culturas e escarificação. Revista Brasileira de Ciência do Solo, Viçosa, MG, v.32, n.4, p.13991407, 2008.

CORREIA, J. C. Efeito de sistema de cultivo na estabilidade de agregados de um Latossolo vermelho-amarelo em Querência, MT. Pesquisa Agropecuária Brasileira, Brasília, v.37, n.2, p.203209, 2002.

EMBRAPA. Manual de métodos de analise de solos. Rio de Janeiro: CNPS- EMBRAPA, 2005. 412p.

FONTENELE,W.; SALVIANO, A. A. C.; MOUSINHO, F. E. P. Atributos físicos de um Latossolo Amarelo sob sistemas de manejo no cerrado piauiense. Revista Ciência Agronômica, Fortaleza, v.40, n.2, p.194-202, 2009.

GAMA-RODRIGUES, E. F.; BARROS, N. F., GAMA-RODRIGUES, A. C., SANTOS, G. A. Nitrogênio, carbono e atividade da biomassa microbiana do solo em plantações de eucalipto.

Revista Brasileira de Ciência do Solo, Viçosa, MG, v.29, n.6, p.893-901, 2005.

GATTO, A.; BARROS, N. F.; NOVAIS, R. F.; SILVA, I. R.; LEITE, L. G.; LEITE, F. P.; VILLANI, E. M. A.. Estoques de carbono no solo e na biomassa em plantações de eucalipto, Revista Brasileira de Ciência do Solo, Viçosa, MG, v.34, n.4, p.1069-1079, 2010. 
JACOMINE, P.K. T.; CAVALCANTI, A. C.; PESSÔA, S. C. P.; BURGOS, N.; MELO FILHO, H. F. R.; LOPES, O. F.; MEDEIROS, L. A. R. Levantamento exploratório - reconhecimento de solos do Estado do Piauí. Rio de Janeiro: EMBRAPASNLCS/SUDENE-DRN, 1986. 782p.

JANDL, R.; LINDNER, M.; VESTERDAL, L; BAUWENS, B.; BARITZ, R.; HAGEDORN, F.; JOHNSON, D. W.; MINKKINEN, K. ; BYRNE, K. A. I. How strongly can forest management influence soil carbon sequestration? Geoderma, Amsterdam, v.137, n.3-4, p.253-268, 2007.

LONGO, R.M.; ESPÍNDOLA, C.R.; RIBEIRO, A.I. Modificações na estabilidade de agregados no solo decorrentes da introdução de pastagens em áreas de cerrado e floresta amazônica. Revista Brasileira Engenharia de Agrícola Ambiental, Campina Grande, v.3, n.2, p.276-280, 1999.

MENDES, I. C.; SOUZA, L. V.; RESCK, D. V. S.; GOMES, A. C. Propriedades biológicas em agregados de um Latossolo vermelho-escuro sob plantio direto no cerrado. Revista Brasileira de Ciência do Solo, Viçosa, MG, v.27, n.3, p.327336, 2003.

MIRANDA, C. C.; CANELLAS, L. P.; NASCIMENTO, M. T. Caracterização da matéria orgânica do solo em Fragmentos de mata atlântica e em plantios abandonados de eucalipto. Revista Brasileira de Ciência do Solo, Viçosa, MG, v.31, n.5, p.905-916, 2007.

PULROLNIK, K.; BARROS, N. F.; SILVA, I. R.; NOVAIS, R. F.; BRANDANI, C. B. Estoques de carbono e nitrogênio em frações lábeis e estáveis da matéria orgânica de solos sob eucalipto, pastagem e cerrado no vale do Jequitinhonha MG. Revista Brasileira de Ciência do Solo, Viçosa, MG, v.33, n.5, p.1125-1136, 2009.

SILVA, R. R.; SILVA, M. L. N.; FERREIRA, M. M. Atributos físicos indicadores da qualidade do solo sob Sistemas de manejo na bacia do alto do Rio Grande. Ciência \& Agrotecnologia, Lavras, v.29, n.4, p.719-730, 2005.
SILVA, V. R.; REINERT, D. J.; REICHERT, J. M. Resistência mecânica do solo à penetração influenciada pelo tráfego de uma colhedora em dois sistemas de manejo do solo. Ciência Rural, Santa Maria, v.30, n.5 p.795-801, 2000.

STOLF, R. Teoria e teste experimental de fórmulas de transformação dos dados de penetrômetro de impacto em resistência do solo. Revista Brasileira de Ciência do Solo, Viçosa, MG, v.15, p.229-235, 1991.

TISDALL, J. M.; OADES, J. M. Organic matter and water-stable agregates in soils. Journal Soil Science, Edinburg, v.33, n.2, p.141-163, 1982.

USDA. Soil survey manual. Washington: DC: Soil Survey Division Staff, 1993. 437p.

VAZQUEZ, L. MYHRE, D. L.; GALLAHER, R. N.; HANLON, E A.; PORTIER, K. M. Soil compaction associated with tillage treatments for soybean. Soil Tillage Research, Oxford, v.13, n.1, p.35-45, 1989.

VERGUTZ, L. NOVAIS, R. F.; SILVA, I. R.; BARROS, N. F.; NUNES, T. N.; PIAU, A. A. M. Mudanças na matéria orgânica do solo causadas pelo tempo de adoção de um sistema agrossilvopastoril com eucalipto. Revista Brasileira de Ciência do Solo, Viçosa, MG, v.34, n.1, p.43-57, 2010.

WILCKE, W.; LILIENFEIN, J. Soil carbon-13 natural abundance under native and managed vegetation in Brazil. Soil Science Society America Journal, Madinson, v.68, n.5, p.827- 832, 2004.

ZINN, Y. L.; RESCK, D. V. S.; SILVA, J. E. Soil organic carbon as affected by afforestation with Eucalyptus and Pinus in the Cerrado region of Brazil. Foresty Ecology Management, Oxford, v.166, n.1, p.285-294, 2002. 